\title{
Prevalence of Intestinal Parasites and Associated Risk Factors for Infection among Rural Communities of Chachoengsao Province, Thailand
}

\author{
Pisit Suntaravitun, Amornrat Dokmaikaw* \\ Department of Public Health, Faculty of Science and Technology, Rajabhat Rajanagarindra University, Chachoengsao 24000, Thailand
}

\begin{abstract}
Intestinal parasitic infections remain a major public health problem in many parts of Thailand, particularly in rural areas. This study aimed to determine the prevalence of intestinal parasitic infections and associated risk factors among the people living in Huai Sai sub-district, Bang Khla district, Chachoengsao Province, central Thailand. A crosssectional survey was carried out from June 2017 to August 2017 which included a total of 224 participants. Stool samples were examined using a simple direct smear and formalin ethyl acetate concentration technique. Association between risk factors and intestinal parasitic infections was assessed using multivariate logistic regression analysis. The overall prevalence of intestinal parasitic infections was $16.1 \%$. Soil-transmitted helminth infections $(14.3 \%)$ were more common than protozoan infections (1.8\%). The most common intestinal parasites were hookworms (6.7\%) followed by Strongyloides stercoralis, (5.0\%), Ascaris lumbricoides (1.3\%) and Trichuris trichiura (1.3\%). Entamoeba histolytica/dispar (1.0\%), Giardia intestinalis $(0.4 \%)$, and Blastocystis hominis $(0.4 \%)$ were the protozoans identified. A high prevalence of infections was found in male participants of $\geq 40$ years who raised dogs in the households and did not wear boots while working fields. Multivariate analysis showed a significant association of intestinal parasitic infections with gender with the adjusted odds ratio (OR) of 2.4 and 95\% confidence interval $(\mathrm{Cl})$ of 1.1-5.2 $(P=0.020)$. The results showed a high prevalence of soiltransmitted helminth infections among adults in rural communities which were particularly apparent regarding the skinpenetrating species of nematodes. A greater focus on intervention is required by improving sanitation and personal hygiene to prevent the spread of intestinal parasitic infections.
\end{abstract}

Key words: Strongyloides stercoralis, hookworm, Ascaris lumbricoides, Trichuris trichiura, Entamoeba histolytica, Entamoeba dispar, Giardia intestinalis, Blastocystis hominis, risk factor, Thailand

\section{INTRODUCTION}

Intestinal parasitic infections are caused by different species of helminths and protozoan parasites. They belong to the neglected tropical diseases (NTDs) [1] group and remain a major public global health problem. Common intestinal parasites in tropical and subtropical areas include soil-transmitted helminths. Globally, it is estimated that 1.45 billion people are infected with soil-transmitted helminths (data as of 2010), resulting in 4.98 years of life lost due to disability (YLDs) and 5.18 million disability-adjusted life years (DALYs) [2]. There are 4 major nematode species of human soil-transmitted helminths, which are also known as geohelminths, namely, (1)

- Received 15 December 2017, revised 7 February 2018, accepted 13 February 2018.

*Corresponding author (amornrat8006@gmail.com)

(c) 2018, Korean Society for Parasitology and Tropical Medicine

This is an Open Access article distributed under the terms of the Creative Commons Attribution Non-Commercial License (http://creativecommons.org/licenses/by-nc/4.0) which permits unrestricted non-commercial use, distribution, and reproduction in any

medium, provided the original work is properly cited. roundworms (Ascaris lumbricoides), (2) whipworms (Trichuris trichiura), and 2 different kinds of hookworms; (3) Ancylostoma duodenale and (4) Necator americanus [2,3]. Humans become infected by accidental ingestion of eggs at their infective stage or through penetration of the skin by infected larvae in soil, depending on the nematode species. The major health issue caused by soil-transmitted helminth infection is the negative effect on the nutritional status, physical growth, and cognitive development of the host, especially in children. Most studies conducted in several countries focused on soil-transmitted helminth infections among preschool-age children (pre-SAC) and school-age children (SAC), while a few reported soiltransmitted helminth infections among adult age groups [3]. The prevalence of soil-transmitted helminth infections is still high among several countries throughout the Association of Southeast Asian Nations (ASEAN), including Thailand [3]. In 2009, the national prevalence rate of intestinal helminthic infections was $18.1 \%$ among Thais with a high prevalence rate of liver fluke and hookworm infections in certain areas of the 
country [4].

Previous studies of the prevalence of intestinal parasites among pre-SAC and SAC showed a low incidence of soiltransmitted helminth infections in Chachoengsao Province $[5,6]$. However, no information was available regarding the prevalence and risk factors of intestinal parasitic infections among the residents of Bang Khla district, Chachoengsao Province. Consequently, this study was undertaken to determine the prevalence and potential risk factors associated with intestinal parasitic infections among people living in Huai Sai sub-district, Bang Khla district, Chachoengsao Province in the central region of Thailand.

\section{MATERIALS AND METHODS}

\section{Study design and area}

A cross-sectional survey was carried out from June 2017 to August 2017 and included people living in 7 rural villages located in Huai Sai sub-district, Bang Khla district, Chachoengsao Province, central Thailand. The study area is located 100 $\mathrm{km}$ east of Bangkok and covers an area of $46 \mathrm{~km}^{2}$ with the geographical location between $13^{\circ} 45^{\prime} 28.8^{\prime \prime} \mathrm{N}$ to $13^{\circ} 51^{\prime} 28.8^{\prime \prime} \mathrm{N}$ and $100^{\circ} 10^{\prime} 51.6^{\prime \prime}$ E to $101^{\circ} 15^{\prime} 39.9^{\prime \prime} \mathrm{E}$ (Fig. 1). Participants were randomly selected from each village using a voluntary sampling method. A total of 224 volunteers were recruited. Data on socio-demographic characteristics and risk factors was collected using a questionnaire.

\section{Stool collection and examination}

Clean plastic containers were distributed to the participants at enrollment with detailed instructions about the procedure for stool specimen collection. All stool samples were collected early in the morning and conserved in ice boxes before transportation to the laboratory at the Department of Biology, Faculty of Science and Technology, Rajabhat Rajanagarindra University. Each specimen was examined for the presence of intestinal parasitic organisms by a simple direct smear and formalin ethyl acetate concentration technique [7]. Parasite identification in positive samples was confirmed using a light microscope.

\section{Ethical considerations}

This study was carried out according to the guidelines as stipulated in the Declaration of Helsinki and all procedures involving human subjects were approved by the Ethics Committee of Rajabhat Rajanagarindra University, Thailand (ap-

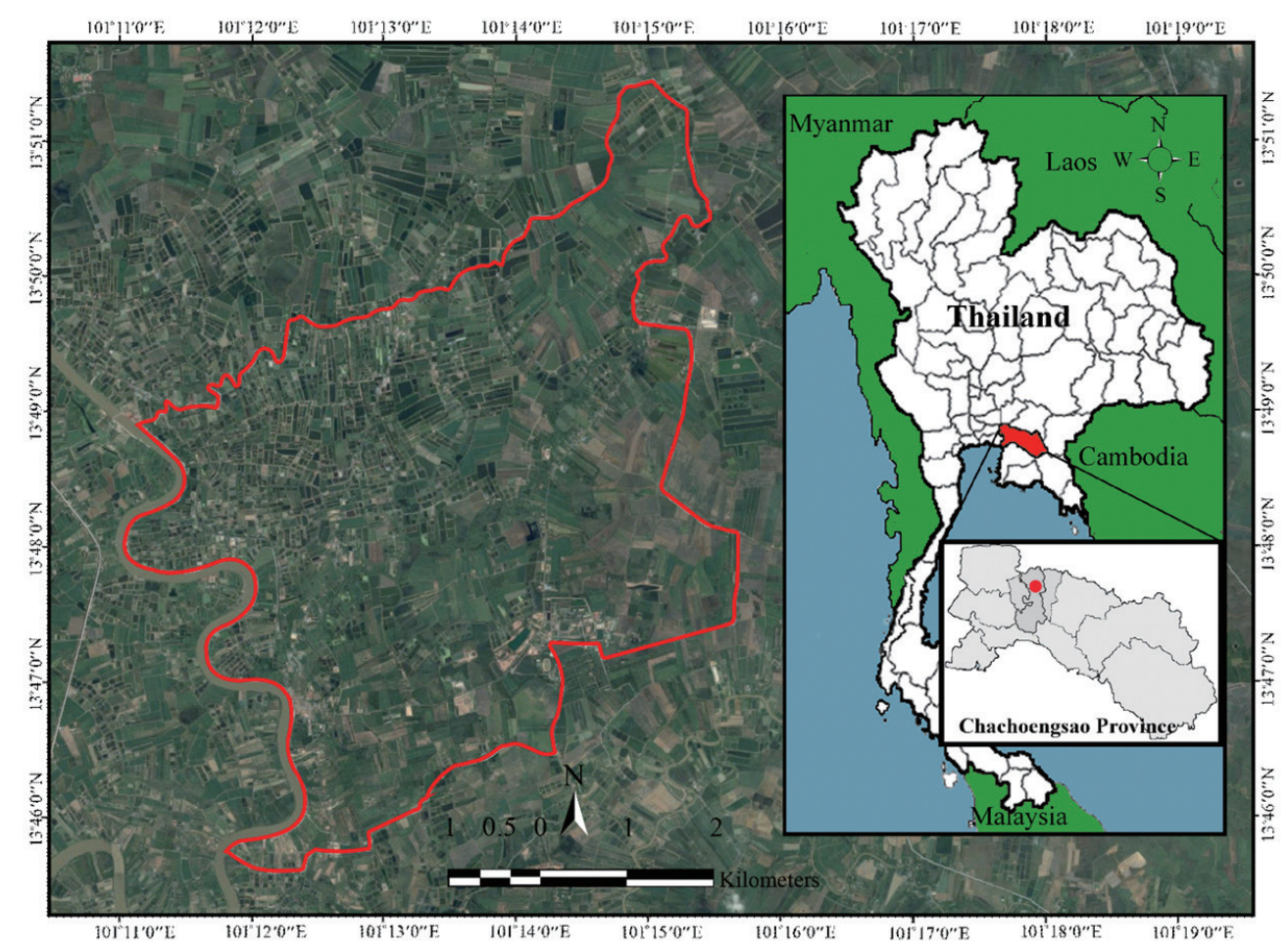

Fig. 1. Map of Thailand showing the study area in Huai Sai sub-district, Bang Khla district, Chachoengsao Province, Thailand. 
proval no. RRUPH 602002). All participants provided their own written consent before submitting stool specimens.

\section{Data analysis}

The Statistical Package for the Social Sciences (SPSS, Chicago, Illinois, USA) for windows version 23 was used to analyze the data. Socio-demographic characteristics of the participants were presented as frequencies and percentages for the categorical variables. Multivariate logistic regression analysis was performed to estimate the odds ratio (OR) and 95\% confidence interval $(95 \% \mathrm{CI})$ to assess the associations between potential risk factors and prevalence of intestinal parasitic infections. A $P$-value of $<0.05$ was considered to be statistically significant.

\section{RESULTS}

\section{Prevalence by socio-demographic characteristics}

The prevalence of intestinal parasites influenced by socio-

Table 1. Prevalence of intestinal parasites influenced by sociodemographic characteristics of 224 participants

\begin{tabular}{|c|c|c|c|}
\hline Characteristic & $\begin{array}{c}\text { No. of } \\
\text { participants }\end{array}$ & $\begin{array}{c}\text { No. } \\
\text { infected }\end{array}$ & $\begin{array}{c}\text { Prevalence } \\
\text { (\%) }\end{array}$ \\
\hline \multicolumn{4}{|l|}{ Gender } \\
\hline Male & 88 & 20 & 22.7 \\
\hline Female & 136 & 16 & 11.8 \\
\hline \multicolumn{4}{|l|}{ Age (year) } \\
\hline$<21$ & 23 & 1 & 4.3 \\
\hline $21-40$ & 47 & 5 & 10.6 \\
\hline $41-60$ & 92 & 19 & 20.7 \\
\hline$>60$ & 62 & 11 & 17.7 \\
\hline \multicolumn{4}{|l|}{ Educational level } \\
\hline Primary school & 162 & 29 & 17.9 \\
\hline Secondary/high school & 50 & 6 & 12.0 \\
\hline Diploma/Bachelor degree & 12 & 1 & 8.3 \\
\hline \multicolumn{4}{|l|}{ Occupation } \\
\hline Agriculture & 129 & 25 & 19.4 \\
\hline Merchant & 25 & 1 & 4.0 \\
\hline Government officer & 5 & 0 & 0.0 \\
\hline Employee & 46 & 8 & 17.4 \\
\hline Other & 19 & 2 & 10.5 \\
\hline \multicolumn{4}{|l|}{ Monthly income (Baht) } \\
\hline$<5,001$ & 36 & 8 & 22.2 \\
\hline $5,001-10,000$ & 89 & 12 & 13.5 \\
\hline $10,001-15,000$ & 53 & 7 & 13.2 \\
\hline$>15,000$ & 46 & 9 & 19.6 \\
\hline \multicolumn{4}{|l|}{ Family members } \\
\hline$<5$ & 190 & 28 & 14.7 \\
\hline$\geq 5$ & 34 & 8 & 23.5 \\
\hline Total & 224 & 36 & 16.1 \\
\hline
\end{tabular}

demographic characteristics are shown in Table 1. A total of 224 participants ( 88 male, 136 female) were included. The overall prevalence of intestinal parasitic infections was $16.1 \%$ (36/224). The prevalence rate was $22.7 \%$ (20/88) in males and $11.8 \%(16 / 136)$ in females. Participants aged 41-60 years old had a higher prevalence rate at 20.7\% (19/92) when compared to other age groups. When classified by education level, the highest prevalence rate was $17.9 \%$ (29/162) for those with primary school education. By occupation, intestinal parasitic infections were most frequent among agricultural workers at $19.4 \%$ (25/129). A high prevalence of intestinal parasites was found in participants with income of less than 5,001 Baht/ month $(22.2 \%, 8 / 36)$ and among families with 5 or more members $(23.5 \%, 8 / 34)$.

\section{Distribution of parasites}

The types of intestinal parasitic infections are shown in Table 2. Seven species of intestinal parasites were identified from the stool specimens of the study participants; 4 species were identified as helminths and the other 3 species were protozoans (Fig. 2). The prevalence of intestinal helminths and protozoans were $14.3 \%$ (32/224) and 1.8\% (4/224), respectively. Soil-transmitted helminths were among the most common intestinal parasites, which included hookworm at 6.7\% (15/224), Strongyloides stercoralis 5.0\% (11/224), Trichuris trichiura 1.3\% (3/224) and Ascaris lumbricoides 1.3\% (3/224). Pathogenic protozoan infections were identified as Entamoeba histolytica/E. dispar 1.0\% (2/224), Giardia intestinalis $0.4 \%(1 / 224)$ and Blastocystis hominis $0.4 \%(1 / 224)$.

\section{Risk factors associated with intestinal parasitic infections}

Univariate and multivariate analysis of risk factors associat-

Table 2. Types of soil-transmitted helminth and intestinal protozoan infections among the 224 participants

\begin{tabular}{lcc}
\hline Type of parasite & No. of infections & Prevalence (\%) \\
\hline Soil-transmitted helminth & 32 & 14.3 \\
Hookworms & 15 & 6.7 \\
Strongyloides stercoralis & 11 & 5.0 \\
Trichuris trichiura & 3 & 1.3 \\
Ascaris lumbricoides & 3 & 1.3 \\
Protozoans & 4 & 1.8 \\
Entamoeba histolytica/dispar & 2 & 1.0 \\
Giardia intestinalis & 1 & 0.4 \\
Blastocystis hominis & 1 & 0.4 \\
Total & 36 & 16.1 \\
\hline
\end{tabular}



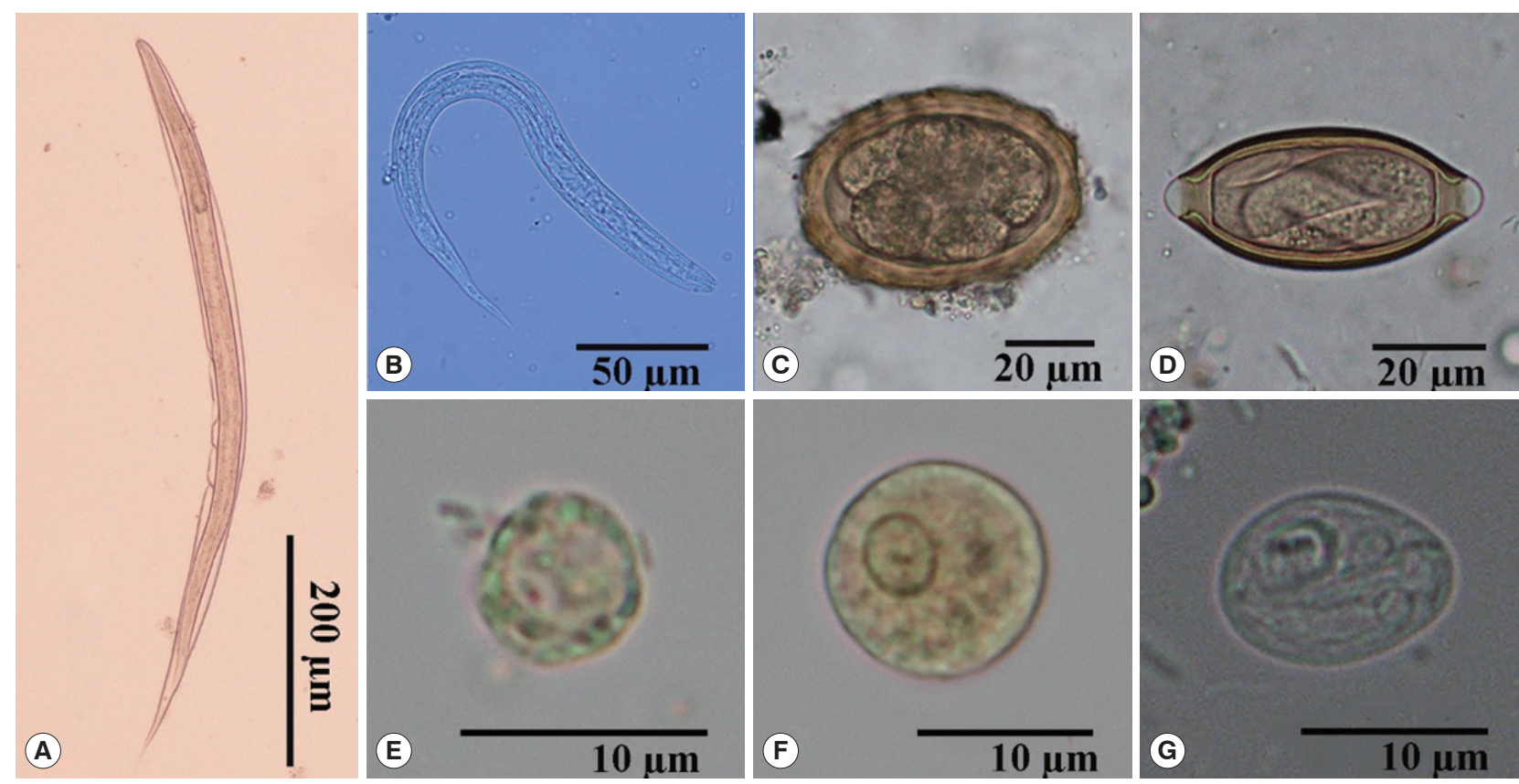

Fig. 2. Morphology of intestinal parasites identified by light microscopy in stool samples. (A) Rhabditiform larva of hookworm ( $\times 100)$. (B) Rhabditiform larva of Strongyloides stercoralis ( $\times 400)$. (C) Egg of Ascaris lumbricoides $(\times 400)$. (D) Egg of Trichuris trichiura ( $\times 400)$. (E) Cyst of Blastocystis hominis (x 1,000). (F) Cyst of Entamoeba histolytica/E. dispar $(\times 1,000)$. (G) Cyst of Giardia intestinalis $(\times 1,000)$.

ed with intestinal parasitic infections are shown in Table 3. No significant association was found between intestinal parasitic infections and participants' level of education, occupation, monthly income, number of family members, raised cats in the household, wearing shoes outside, eating undercooked food, washing hands before meals, open defecation, use of antiparasitic drugs and drinking water treatment $(P>0.05)$. However, univariate analysis identified 4 risk factors associated with intestinal parasitic infections, which included gender (Crude $\mathrm{OR}=2.2 ; 95 \% \mathrm{CI}=1.1-4.5 ; P=0.032$ ), age groups (Crude $\mathrm{OR}=2.6 ; 95 \% \mathrm{CI}=1.0-6.5 ; P=0.045)$, raised dogs in the household (Crude $\mathrm{OR}=2.1 ; 95 \% \mathrm{CI}=1.0-4.4 ; P=0.043$ ) and wearing boots in the field (Crude $\mathrm{OR}=2.2 ; 95 \% \mathrm{CI}=1.0-4.5$; $P=0.038$ ). After adjusting for potential confounding factors by multivariate logistic regression analysis, only one of the 4 risk factors, namely gender, showed a significant association between the prevalence of intestinal parasites (Adjusted $\mathrm{OR}=2.4$; $95 \% \mathrm{CI}=1.1-5.2 ; P=0.020)$.

\section{DISCUSSION}

The overall prevalence of intestinal parasitic infections among the entire tested participant group who live in rural communities in Huai Sai sub-district, Bang Khla district, Cha- choengsao Province was $16.1 \%$. This was slightly lower or comparable to the findings of previous studies conducted on participants living across Thailand during a national survey of helminthiasis in Thailand [4]. Moreover, these results were lower than previously reported among gardeners who were tested in Chanthaburi Province [8] and northeastern Thai rural residents tested in Khon Kaen Province $[9,10]$. In particular, Opisthorchis viverrini was the most predominant parasite in the northeastern regions, while the central regions of Thailand had low prevalence rates [4]. However, previous studies recorded high prevalence of $O$. viverrini infection in a rural community in Baan Nayao Village, Sanamchaiket District, Chachoengsao Province [11]. This finding differed from our results where O. viverrini infection was not found. This variation may be due to differences in population consumption behaviour of raw freshwater fish in each area.

Findings from our study demonstrated that the prevalence of soil-transmitted helminth infection $(14.3 \%)$ was significantly higher than protozoan infection (1.8\%) among the adult age groups and contradicts previous findings concerning pre-SAC and SAC which have shown a low prevalence of soiltransmitted helminth infections in the same province [5,6]. In addition, our results also contrasted with previous studies among gardeners living and working in Chanthaburi Province 
Table 3. Univariate and multivariate analysis of intestinal parasitic infections and potential risk factors among the 224 participants

\begin{tabular}{|c|c|c|c|c|c|c|}
\hline Risk factor & $\begin{array}{l}\text { No. } \\
\text { examined }\end{array}$ & $\begin{array}{l}\text { No. of infections } \\
\text { (\%) }\end{array}$ & $\begin{array}{l}\text { Crude OR } \\
(95 \% \mathrm{Cl})\end{array}$ & $P$-value & $\begin{array}{l}\text { Adjusted OR } \\
(95 \% \mathrm{Cl})\end{array}$ & $P$-value \\
\hline $\begin{array}{l}\text { Gender } \\
\text { Male } \\
\text { Female }\end{array}$ & $\begin{array}{r}88 \\
136\end{array}$ & $\begin{array}{l}20(22.7) \\
16(11.8)\end{array}$ & $2.2(1.1,4.5)$ & $0.032^{*}$ & $2.4(1.1,5.2)$ & $0.020^{*}$ \\
\hline $\begin{array}{l}\text { Age (year) } \\
\quad \geq 40 \\
<40\end{array}$ & $\begin{array}{r}154 \\
70\end{array}$ & $\begin{array}{c}30(19.5) \\
6(8.6)\end{array}$ & $2.6(1.0,6.5)$ & $0.045^{\star}$ & $2.6(0.9,6.8)$ & 0.051 \\
\hline $\begin{array}{l}\text { Educational level } \\
\text { Primary school } \\
\text { More than primary school }\end{array}$ & $\begin{array}{r}162 \\
62\end{array}$ & $\begin{array}{r}29(17.9) \\
7(11.3)\end{array}$ & $1.7(0.7,4.1)$ & 0.232 & - & - \\
\hline $\begin{array}{l}\text { Occupation } \\
\text { Agriculture } \\
\text { Other }\end{array}$ & $\begin{array}{r}129 \\
95\end{array}$ & $\begin{array}{l}25(19.4) \\
11(11.6)\end{array}$ & $1.8(0.9,3.9)$ & 0.12 & - & - \\
\hline $\begin{array}{l}\text { Monthly income (Baht) } \\
\quad<10,000 \\
\geq 10,000\end{array}$ & $\begin{array}{r}125 \\
99\end{array}$ & $\begin{array}{l}20(16.0) \\
16(16.2)\end{array}$ & $1.0(0.5,2.0)$ & 0.974 & - & - \\
\hline $\begin{array}{l}\text { Family members } \\
<5 \\
\geq 5\end{array}$ & $\begin{array}{r}190 \\
34\end{array}$ & $\begin{array}{r}28(14.7) \\
8(23.5)\end{array}$ & $0.6(0.2,1.4)$ & 0.203 & - & - \\
\hline $\begin{array}{l}\text { Raised dogs } \\
\text { Yes } \\
\text { No }\end{array}$ & $\begin{array}{l}102 \\
122\end{array}$ & $\begin{array}{l}22(21.6) \\
14(11.5)\end{array}$ & $2.1(1.0-4.4)$ & $0.043^{*}$ & $2.0(0.9,4.2)$ & 0.077 \\
\hline $\begin{array}{l}\text { Raised cats } \\
\text { Yes } \\
\text { No }\end{array}$ & $\begin{array}{r}61 \\
163\end{array}$ & $\begin{array}{r}8(13.1) \\
28(17.2)\end{array}$ & $0.7(0.3,1.7)$ & 0.462 & - & - \\
\hline $\begin{array}{l}\text { Wearing shoes outside } \\
\text { No } \\
\text { Yes }\end{array}$ & $\begin{array}{r}48 \\
176\end{array}$ & $\begin{array}{r}6(12.5) \\
30(17.0)\end{array}$ & $0.7(0.3,1.8)$ & 0.449 & - & - \\
\hline $\begin{array}{l}\text { Wearing boots in the field } \\
\text { No } \\
\text { Yes }\end{array}$ & $\begin{array}{r}95 \\
129\end{array}$ & $\begin{array}{l}21(22.1) \\
15(11.6)\end{array}$ & $2.2(1.0,4.5)$ & $0.038^{*}$ & $1.9(0.9,4.0)$ & 0.095 \\
\hline $\begin{array}{l}\text { Eating undercooked food } \\
\text { Yes } \\
\text { No }\end{array}$ & $\begin{array}{r}145 \\
79\end{array}$ & $\begin{array}{l}22(15.2) \\
14(17.7)\end{array}$ & $0.8(0.4,1.7)$ & 0.62 & - & - \\
\hline $\begin{array}{l}\text { Washing hands before meals } \\
\text { No } \\
\text { Yes }\end{array}$ & $\begin{array}{r}31 \\
193\end{array}$ & $\begin{array}{r}7(22.6) \\
29(15.0)\end{array}$ & $1.6(0.7,4.2)$ & 0.292 & - & - \\
\hline $\begin{array}{l}\text { Open defecation } \\
\text { Yes } \\
\text { No }\end{array}$ & $\begin{array}{r}94 \\
130\end{array}$ & $\begin{array}{l}19(20.2) \\
17(13.1)\end{array}$ & $1.7(0.8,3.4)$ & 0.154 & - & - \\
\hline $\begin{array}{l}\text { Use of antiparasitic drugs } \\
\text { No } \\
\text { Yes }\end{array}$ & $\begin{array}{r}203 \\
21\end{array}$ & $\begin{array}{c}35(17.2) \\
1(4.8)\end{array}$ & $4.2(0.5,32.0)$ & 0.171 & - & - \\
\hline $\begin{array}{l}\text { Drinking water treatment } \\
\text { No } \\
\text { Yes }\end{array}$ & $\begin{array}{r}83 \\
141\end{array}$ & $\begin{array}{l}13(15.7) \\
23(16.3)\end{array}$ & $1.1(0.5,2.2)$ & 0.898 & - & - \\
\hline
\end{tabular}

OR, odds ratio.

${ }^{*} P$-value $\leq 0.05$.

[8]. We found that the prevalence of intestinal helminthiasis was higher than previously observed in other areas of Thailand as between $5.6 \%$ and $6.2 \%[12,13]$ but was lower than the national prevalence rate (18.1\%) [4]. Other authors have also reported a slightly lower prevalence of protozoan infections, which includes E. histolytica/dispar, G. intestinalis and B. hominis, agreeing with other studies and ranging from $3.0 \%$ to
$4.4 \%[9,10]$. These differences in prevalence rate may be due to diversity in geographic areas, age groups, level of education, income, personal hygiene behaviour and occupation of the participants.

In our study, the most common intestinal soil-transmitted helminths found were hookworms with a prevalence rate of $6.7 \%$, similar to results reported by the national survey of hel- 
minthiasis in Thailand where a prevalence rate of $6.5 \%$ was found [4] but lower than previously reported in Thailand (ranging from $8.0 \%$ to $14.5 \%)[10,14,15]$, Myanmar (8.7\%) [16], Malaysia (11.8\%) [17], Lao People’s Democratic Republic (Lao PDR) (25.0\%) [18] and Cambodia (ranging from 9.6 to 57.4\%) $[19,20]$. The second most dominant parasite was $S$. stercoralis with a prevalence rate of $5.0 \%$, which concurred with a previous study by an author who determined the infection rate to be 5.5\% among gardeners in Chanthaburi Province [8], Eastern Thailand. This result was higher than reported by previous authors for similar populations in the range of $0.9 \%$ to $2.9 \%$ $[4,10,12-14]$ but lower than reports from Khon Kaen Province (9.5\%) [9]. The lowest prevalence rate of soil-transmitted helminth infection was $1.3 \%$ for T. trichiura and A. lumbricoides. Similar results were reported by several authors in Thailand (range 0.0-1.2\%) [4,9,10,12-14] but differences were found in other countries such as Myanmar (ranging from 5.3 to 18.1\%) [16], Malaysia (ranging from 33.2 to 48.4\%) [17], Lao PDR (ranging from 8.5 to $11.6 \%$ ) [18] and Cambodia (ranging 4.1 to 4.6\%) [20]. In general, prevalence rates of T. trichiura and A. lumbricoides infections were higher among SAC compared with older age groups. Conversely, the prevalence rate of hookworm infection was highest in the 20-29 age group and older age groups in Thailand [3]. In our study, the prevalence rate of intestinal parasitic infections in the older age groups ( $\geq 40$ years) was higher than in the younger age groups ( $<40$ years), similar to the results as exhibited in other studies $[9,10,14]$. This may be because younger age groups are less exposed to sources of infective-stage larvae (hookworm and S. stercoralis) living in soil.

Our study also assessed the possible association of intestinal parasitic infection with potential risk factors among the participants. The presence of parasitic infections was not significantly associated with participants' level of education, occupation, monthly income, number of family members, raised cats in the household, wearing shoes outside, eating undercooked food, washing hands before meals, open defecation, use of antiparasitic drugs and drinking water treatment. Our results were compatible with previous studies in Thailand $[6,14,15,21]$. Multivariate analysis demonstrated a significant association between the prevalence of parasitic infections and gender difference. Males had a significantly higher prevalence rate of parasitic infections than females with odds increased approximately 2.4 times, possibly because of the higher rates of occupational exposure through work activities [4]. However, univariate analysis showed that age groups, raised dogs in the household and wearing boots in the field were also significantly associated with the prevalence of parasitic infections. Most participants were adults aged $\geq 40$ years and worked in agriculture. Consequently, these age groups had a greater risk of exposure to hazardous factors in an agricultural working environment. An effective way to reduce the risk of infection is to wear boots as protection against hazardous environmental threats such as soil-transmitted nematodes instead of walking barefoot. Our findings indicated that the prevalence of parasitic infection was significantly associated with raising dogs in the household. Similar results were reported from Nanglae sub-district, Chiang Rai Province [21] in the northern region and Nopphitam district Nakhon Si Thammarat Province [14] in the southern region of Thailand. Keeping dogs in a house may be an important factor as animal reservoir hosts for the epidemiology of intestinal zoonotic parasites, particularly geohelminths such as hookworms and $S$. stercoralis which can be transmitted to human hosts mainly through skin contact with contaminated soil containing infective filariform larvae. Several studies have reported significant associations between other potential risk factors and intestinal parasitic infections, suggesting that keeping cats at home [6], walking barefoot [15], raising buffaloes close to the house [15], consumption of raw meat [21] and source of drinking water [22] were risk factors. The differences recorded by looking at risk factors may be because of the varying environmental conditions in each area.

In conclusion, our results show a high prevalence rate of soil-transmitted helminth infections among adult age groups living in the rural communities of Bang Khla district, Chachoengsao Province, central Thailand. These infections result mainly from skin-penetrating species of nematodes. Therefore, focus on intervention should concentrate on improving the sanitation and personal hygiene of the population to reduce intestinal parasitic infections in this area. Further epidemiological studies should be performed to evaluate zoonotic intestinal parasites of dogs and environmental contamination with infective stages of parasites that are dangerous to human health.

\section{ACKNOWLEDGMENTS}

We are grateful to all the study participants and their families for their cooperation in this study. We would like to thank the staff of the Department of Biology, Faculty of Science and Technology, Rajabhat Rajanagarindra University, Thailand for 
providing the use of their laboratory equipments. This work was supported by the Institute of Research and Development, Rajabhat Rajanagarindra University, Thailand.

\section{CONFLICT OF INTEREST}

The authors declare no conflict of interest.

\section{REFERENCES}

1. Hotez PJ, Bottazzi ME, Strych U, Chang LY, Lim YA, Goodenow MM, AbuBakar S. Neglected tropical diseases among the Association of Southeast Asian Nations (ASEAN): overview and update. PLoS Negl Trop Dis 2015; 9: e0003575.

2. Pullan RL, Smith JL, Jasrasaria R, Brooker SJ. Global numbers of infection and disease burden of soil-transmitted helminth infections in 2010. Parasit Vectors 2014; 7: 37.

3. Dunn JC, Turner HC, Tun A, Anderson RM. Epidemiological surveys of, and research on, soil-transmitted helminths in Southeast Asia: a systematic review. Parasit Vectors 2016; 9: 31.

4. Wongsaroj T, Nithikathkul C, Rojkitikul W, Nakaia W, Royal L, Rammasut P. National survey of helminthiasis in Thailand. Asian Biomed 2014; 8: 779-783.

5. Suntaravitun P, Dokmaikaw A. Prevalence of intestinal protozoan infections among schoolchildren in Bang Khla District, Chachoengsao Province, central Thailand. Asian Pac J Trop Dis 2017; 7: 523-526.

6. Boontanom P, Mungthin M, Tan-Ariya P, Naaglor T, Leelayoova S. Epidemiology of giardiasis and genotypic characterization of Giardia duodenalis in preschool children of a rural community, central Thailand. Trop Biome 2011; 28: 32-39.

7. Garcia SL. Diagnostic Medical Parasitology. 6th ed. Washington, USA. ASM press. 2016.

8. Kitvatanachai S, Rhongbutsri P. Using Mini Parasep ${ }^{\circledR S F}$ to determine intestinal parasitic infections comparing to conventional methods in gardener of Chanthaburi Province, Thailand. Asian Pac J Trop Dis 2017; 7: 596-600.

9. Boonjaraspinyo S, Boonmars T, Kaewsamut B, Ekobol N, Laummaunwai P, Aukkanimart R, Wonkchalee N, Juasook A, Sriraj P. A cross-sectional study on intestinal parasitic infections in rural communities, northeast Thailand. Korean J Parasitol 2013; 51: 727-734.

10. Songserm N, Promthet S, Wiangnon S, Sithithaworn P. Prevalence and co-infection of intestinal parasites among Thai rural residents at high-risk of developing cholangiocarcinoma: a crosssectional study in a prospective cohort study. Asian Pac J Cancer Prev 2012; 13: 6175-6179.

11. Suwannahitatorn P, Klomjit S, Naaglor T, Taamasri P, Rangsin R, Leelayoova S, Mungthin M. A follow-up study of Opisthorchis viverrini infection after the implementation of control program in a rural community, central Thailand. Parasit Vectors 2013; 6: 188.

12. Vitta A, Polseela R, Bunchu N, Waree P, Thongwat D, Tangchaisuriya $\mathrm{U}$, Poomidonming $\mathrm{W}$. Intestinal helminthiases in two communities of Phitsanulok Province, northern Thailand. J Trop Med Parasitol 2012; 35: 1-5.

13. Kaewpitoon SJ, Loyd RA, Kaewpitoon N. A Cross-sectional survey of intestinal helminthiases in rural communities of Nakhon Ratchasima province, Thailand. J Med Assoc Thai 2015; 98 (suppl 4): 27-32.

14. Punsawad C, Phasuk N, Bunratsami S, Thongtup K, Siripakonuaong N, Nongnaul S. Prevalence of intestinal parasitic infection and associated risk factors among village health volunteers in rural communities of southern Thailand. BMC Public Health 2017; $17: 564$.

15. Jiraanankul V, Aphijirawat W, Mungthin M, Khositnithikul R, Rangsin R, Traub RJ, Piyaraj P, Naaglor T, Taamasri P, Leelayoova $\mathrm{S}$. Incidence and risk factors of hookworm infection in a rural community of central Thailand. Am J Trop Med Hyg 2011; 84: 594-598.

16. Dunn JC, Bettis AA, Wyine NY, Lwin AMM, Lwin ST, Su KK, Sein MM, Tun A, Maung NS, Anderson RM. A cross-sectional survey of soil-transmitted helminthiases in two Myanmar villages receiving mass drug administration: epidemiology of infection with a focus on adults. Parasit Vectors 2017; 10: 374.

17. Ngui R, Shafie A, Chua KH, Mistam MS, Al-Mekhlafi HM, Sulaiman WW, Mahmud R, Lim YA. Mapping and modelling the geographical distribution of soil-transmitted helminthiases in Peninsular Malaysia: implications for control approaches. Geospat Health 2014; 8: 365-376.

18. Laymanivong S, Hongvanthong B, Keokhamphavanh B, Phommasansak M, Phinmaland B, Sanpool O, Maleewong W, Intapan PM. Current status of human hookworm infections, ascariasis, trichuriasis, schistosomiasis mekongi and other trematodiases in Lao People's Democratic Republic. Am J Trop Med Hyg 2014; 90: 667-669.

19. Inpankaew T, Schär F, Dalsgaard A, Khieu V, Chimnoi W, Chhoun C, Sok D, Marti H, Muth S, Odermatt P, Traub RJ. High prevalence of Ancylostoma ceylanicum hookworm infections in humans, Cambodia, 2012. Emerg Infect Dis 2014; 20: 976-982.

20. Yong TS, Chai JY, Sohn WM, Eom KS, Jeoung HG, Hoang EH, Yoon CH, Jung BK, Lee SH, Sinuon M, Socheat D. Prevalence of intestinal helminths among inhabitants of Cambodia (20062011). Korean J Parasitol 2014; 52: 661-666.

21. Ruankham W, Bunchu N, Koychusakun P. Prevalence of helminthic infections and risk factors in villagers of Nanglae Sub-District, Chiang Rai province, Thailand. J Med Assoc Thai 2014; 97 (suppl 4): 29-35.

22. Apidechkul T. Prevalence and risk factors of intestinal parasitic infections among hill tribe schoolchildren, northern Thailand. Asian Pac J Trop Dis 2015; 5: 695-699. 
